\title{
Laparoscopic surgery for colorectal liver metastases: moving forward while keeping feet on the ground
}

\author{
Mariano Cesare Giglio, Roberto Ivan Troisi \\ Division of HPB, Minimally Invasive and Robotic Surgery, Department of Clinical Medicine and Surgery, Federico II University Hospital, Naples, \\ Italy \\ Correspondence to: Roberto Ivan Troisi, MSc, MD, PhD, FEBS. Department of Clinical Medicine and Surgery, Federico II University, via Sergio \\ Pansini 5, 80131 Naples, Italy. Email: roberto.troisi@unina.it. \\ Comment on: Syn NL, Kabir T, Koh YX, et al. Survival Advantage of Laparoscopic Versus Open Resection For Colorectal Liver Metastases: A \\ Meta-analysis of Individual Patient Data From Randomized Trials and Propensity-score Matched Studies. Ann Surg 2020;272:253-65.
}

Submitted Mar 18, 2020. Accepted for publication Apr 01, 2020.

doi: 10.21037/hbsn.2020.04.06

View this article at: http://dx.doi.org/10.21037/hbsn.2020.04.06

The laparoscopic approach to the surgical treatment of colorectal liver metastases (CRLMs) is supported nowadays by high evidence (1). In the hand of expert surgeons, patients undergoing laparoscopic liver surgery (LLS) for CLRMs benefit from a number of advantages, including a shorter postoperative in-hospital stay, less pain, fewer complications and a faster recovery (1). More importantly, all these profits are achieved while preserving the oncological outcomes, which are not-inferior to those achieved by open procedures (1). Recently published longterm results of randomized trials have shown similar patient survival after laparoscopic and open surgery for CRLM (2).

As surgeons with a great interest in the LLS since its beginning, we were excited to read in Annals of Surgery the recent meta-analysis by Syn et al. (3). These colleagues computed the results from randomized trials and studies using propensity-score matching (PSM), which compared open and laparoscopic surgery for CRLMs. They found a survival advantage for patients undergoing LLS, a result which indeed surprises the surgical community, engaged until today to prove the non-inferiority of the laparoscopic approach.

Several hypotheses are postulated to explain the improved survival following LLS (3). These include the reduced postoperative morbidity and the shorter recovery, which both lead to an earlier resume of chemotherapy $(4,5)$. LLS is also claimed to be performed by more experienced surgeons and more frequently with a parenchymal-sparing approach, which reduces the risk of postoperative liver failure and eases repeat liver resections. Finally, LLS may preserves immunesurveillance by reducing the surgical stress and, compared to open surgery, may lead to an inferior inflammatory boost $(6,7)$, which has been shown to promote metastatic growth. However these data are still controversial and more studies are needed to clarify the role of inflammation in open and laparoscopic surgery of CRLM. Many of these assumptions are sharable, although some (i.e., surgeon experience and the parenchymal-preserving approach) represent a potential confounding factor rather than a real advantage within this comparison.

Nonetheless, even the most avid supporters of LLS should doubt that the findings by Syn et al. could be the result of a patient selection bias, despite the very complex methodology used for this meta-analysis.

Notably, in this work the survival advantage favouring LLS is sustained only by PSM studies (see subgroup analysis). Propensity score balances groups for known confounders, and the authors assume that all potential confounders were balanced in all the studies, with no need of further adjustment. At regard, it is worthy to note that the included thirteen PSM studies controlled for a median number of 9 confounders, varying from 4 to 18 variables. This means that study were indeed heterogeneous for the matching criteria. In addition, survival of patients undergoing surgery for CRLMS depends on a number of prognostic factors which include the number of metastases (8), nodal status (8), differentiation (8) and site 
of the primary tumour (9), and the response to neoadjuvant chemotherapy (10). Even though all PSM studies matched patients according to the number of metastases, only seven, six and five of the included studies matched patients for site, nodal status and differentiation of the primary tumour, respectively. No study took into account the response to the neoadjuvant chemotherapy, in patients who received it. These prognostic factors, especially the last one, could be to some extent determinant of the patient selection for one or the other treatment.

As meta-analysis can detect statistical significant differences while single studies cannot, similarly metaanalysis can amplify bias of single studies bringing them to a significance level. To stay in line with a famous saying about meta-analysis (i.e., "comparing apples and oranges"), in this case the risk is to merge many apples, each one with a small bite, and to obtain a bigger apple with a big hole inside.

In the recent years big steps forward have been made in the surgical literature to understand the real role of LLS in patients with liver disease. First level evidence has come up for CLRMs, supporting the use of LLS, and, step-bystep, we should continue on this way, waiting for the longterm results of the OSLO-COMET and further comingup randomized trials. These studies will need to confirm the findings by Syn et al., that, in the meanwhile, should be accompanied by a wise caution, since big numbers and complex methodology cannot always go beyond the limits of limited-quality data.

\section{Acknowledgments}

Funding: None.

\section{Footnote}

Provenance and Peer Review: This article was commissioned by the editorial office, Hepatobiliary Surgery and Nutrition. The article did not undergo external peer review.

Conflicts of Interest: Both authors have completed the ICMJE uniform disclosure form (available at http://dx.doi. org/10.21037/hbsn.2020.04.06). The authors have no conflicts of interest to declare.

Ethical Statement: The authors are accountable for all aspects of the work in ensuring that questions related to the accuracy or integrity of any part of the work are appropriately investigated and resolved.
Open Access Statement: This is an Open Access article distributed in accordance with the Creative Commons Attribution-NonCommercial-NoDerivs 4.0 International License (CC BY-NC-ND 4.0), which permits the noncommercial replication and distribution of the article with the strict proviso that no changes or edits are made and the original work is properly cited (including links to both the formal publication through the relevant DOI and the license). See: https://creativecommons.org/licenses/by-nc-nd/4.0/.

\section{References}

1. Fretland ÅA, Dagenborg VJ, Bjørnelv GMW, et al. Laparoscopic Versus Open Resection for Colorectal Liver Metastases: The OSLO-COMET Randomized Controlled Trial. Ann Surg 2018;267:199-207.

2. Fretland ÅA, Aghayan D, Edwin B. Long-term survival after laparoscopic versus open resection for colorectal liver metastases. J Clin Oncol 2019;37:LBA3516.

3. Syn NL, Kabir T, Koh YX, et al. Survival Advantage of Laparoscopic Versus Open Resection For Colorectal Liver Metastases: A Meta-analysis of Individual Patient Data From Randomized Trials and Propensity-score Matched Studies. Ann Surg 2020;272:253-65.

4. Mbah N, Agle SC, Philips P, et al. Laparoscopic hepatectomy significantly shortens the time to postoperative chemotherapy in patients undergoing major hepatectomies. Am J Surg 2017;213:1060-4.

5. Kawai T, Goumard C, Jeune F, et al. Laparoscopic liver resection for colorectal liver metastasis patients allows patients to start adjuvant chemotherapy without delay: a propensity score analysis. Surg Endosc 2018;32:3273-81.

6. Kasai M, Van Damme N, Berardi G, et al. The inflammatory response to stress and angiogenesis in liver resection for colorectal liver metastases: a randomized controlled trial comparing open versus laparoscopic approach. Acta Chir Belg 2018;118:172-80.

7. Fretland AA, Sokolov A, Postriganova N, et al. Inflammatory Response After Laparoscopic Versus Open Resection of Colorectal Liver Metastases: Data From the Oslo-CoMet Trial. Medicine (Baltimore) 2015;94:e1786.

8. Primrose J, Falk S, Finch-Jones M, et al. Systemic chemotherapy with or without cetuximab in patients with resectable colorectal liver metastasis: the New EPOC randomised controlled trial. Lancet Oncol 2014;15:601-11.

9. Engstrand J, Nilsson H, Strömberg C, et al. Colorectal cancer liver metastases - a population-based study on 
incidence, management and survival. BMC Cancer 2018;18:78.

10. Vigano L, Darwish SS, Rimassa L, et al. Progression

Cite this article as: Giglio MC, Troisi RI. Laparoscopic surgery for colorectal liver metastases: moving forward while keeping feet on the ground. HepatoBiliary Surg Nutr 2021;10(1):107-109. doi: 10.21037/hbsn.2020.04.06 of Colorectal Liver Metastases from the End of Chemotherapy to Resection: A New Contraindication to Surgery? Ann Surg Oncol 2018;25:1676-85. 